\title{
Within-brood social status and consequences for winter hierarchies amongst Mallard Anas platyrhynchos ducklings
}

\author{
Maud Poisbleau • Matthieu Guillemain · \\ Laurent Demongin · David Carslake · \\ Joan David
}

Received: 27 February 2008/Revised: 31 May 2008 / Accepted: 19 June 2008 / Published online: 16 July 2008

(C) Dt. Ornithologen-Gesellschaft e.V. 2008

\begin{abstract}
Juveniles of many birds establish dominance hierarchies within family social units, only to leave and compete to acquire dominance status in new social groups. Little is known about the role of sex, body mass, size or experience during the duckling period on subsequent dominance rank and adult social relationships. We used captive Mallard Anas platyrhynchos ducklings to test for the role of individual characteristics and growth parameters in establishing within-brood hierarchies, the maintenance of within-brood hierarchies in the subsequent wintering group and differences in social ranks between broods. Strong stable linear hierarchies were present within each brood and, later, within each phase of the winter. There was a reorganisation of the hierarchical order between the duckling period and early winter, but only few modifications afterwards during the winter. None of the tested "hatching", "duckling" and "adult" traits explained either the within-brood or the winter hierarchies, but winter rank was related to brood of origin with ducklings from the same brood having similar social ranks. These differences between broods were maintained through the whole winter
\end{abstract}

Communicated by P.H. Becker.

M. Poisbleau · L. Demongin · D. Carslake · J. David Centre d'Etudes Biologiques de Chizé, CNRS-UPR 1934, 79360 Beauvoir-sur-Niort, France

\section{Guillemain}

Office National de la Chasse et de la Faune Sauvage,

CNERA Avifaune Migratrice, La Tour du Valat, Le Sambuc, 13200 Arles, France

M. Poisbleau ( $\square)$

Max Planck Institute for Ornithology, Vogelwarte Radolfzell,

Schlossallee 2, 78315 Radolfzell, Germany

e-mail: poisbleau@orn.mpg.de in most cases, though one brood drastically progressed in the hierarchy during late-winter. These results suggest that the factors affecting the establishment of social relationships within broods differ from those in winter groups, and that brood-related mechanisms influence social relationships during winter. We discuss our results in the light of direct and indirect maternal influence.

Keywords Within-brood social dominance relationships - Winter social dominance relationships . Growth · Duckling · Heritability

\section{Introduction}

Social dominance relationships exist in most group-living animals (Huntingford and Turner 1987; Krause and Ruxton 2002). Stable dominance hierarchies may limit the costs of interactions with conspecifics, by reducing aggressive interactions (Rowell 1974; Bernstein 1981; Archer 1988). Dominant individuals may gain privileged access to resources such as food, mates or shelter (Appleby 1980; Brodsky et al. 1988; Kotrschal et al. 1993), but achieving and maintaining a high social status may be costly (Bryant and Newton 1994; Creel 2001; Buchanan et al. 2001). Although factors affecting social status have been widely studied (de Wall 1989; Piper 1997; Drummond 2006), little is known about the effect that factors operating within broods during growth may have on subsequent adult social status and relationships. It has simply been observed that, for example domestic pigs Sus scrofa born in larger litters were more aggressive as adults (D'Eath and Lawrence 2004), while among broods of Japanese Quails Coturnix japonica, the number of same-sex siblings, the withinbrood social rank of chicks and parental social status were 
all associated with the outcome of post-brood interactions between chicks and strangers (Boag and Alway 1981; Boag 1982). However, it is difficult to determine how genetic and environmental conditions during development interact (Barrette 1993; Capitanio 1993; Moore 1993; Dewsbury 1994; Getty and Capaldi 1994).

In many bird species, one or both parents protect the offspring until fledging (e.g. Barash 1975; Tinkler et al. 2007). After growing up with only their own family, juveniles often join new social groups where they may have to compete to acquire a dominance status. Mallard Anas platyrhynchos ducklings (average brood size 7-14 young) and their mother form a stable family unit from hatching until the age of 2 months (Géroudet 1999). When the mother leaves this group, the ducklings remain together for a few more weeks before joining other broods for migration towards the wintering grounds (Géroudet 1999), where social relationships may play an important role in resource access (Poisbleau et al. 2005a). It is likely that siblings winter in the same areas but little is known of the composition of winter social groups (Géroudet 1999). However, observations on captive ducks suggest that Mallards may be socially organised according to a stable linear hierarchy during winter, and that individual winter social rank correlates with morphological (such as body size and body mass) and hormonal (such as testosterone and corticosterone levels) variables (Hoysak and Ankney 1996; Poisbleau et al. 2005a, b). However, these factors do not wholly or adequately explain acquisition of rank, and other factors linked with earlier periods of life may also play a role in subsequent dominance hierarchies. In particular, early life-history traits at hatching or during the duckling period may have a greater effect later in life than previously thought (Stahlberg 1974; Kalas 1977). To test this idea, we followed six different broods of captive Mallards from hatching through the next winter. We first assessed the dominance hierarchies within each brood in order to test:

(1) The role of sex, hatching order, body mass and size on within-brood hierarchy. Sex as well as the hatching order could affect hatching body mass or body size and determine social relationships within broods. In twochick broods of the Blue-footed Booby Sula nebouxii, while females are heavier and bigger than males, the first-hatched chick becomes dominant whatever its sex because the 4-day hatching interval provides it with advantages in size, mass and maturity (Drummond et al. 1991; Drummond and Osorno 1992). Although most Mallards from the same brood hatch within the same 24-h period, inter-individual differences in body mass, size, mobility and maturity might influence the outcome of aggressive interactions, with the oldest, heaviest or largest birds being dominant.

(2) The role of growth rate on within-brood hierarchy. Precocious ducklings (showing faster growth) may have physical advantages over siblings. Alternatively, early within-brood social experiences (i.e. first encounters with opponents during the first weeks of life) may or may not interact with growth parameters to affect the within-brood hierarchy. Early social experiences may also be predominant over subsequent physical differences in establishing and maintaining within-brood hierarchies (Drummond and Osorno 1992), so later growth parameters may not affect established within-brood ranks.

After the duckling period, we assessed the dominance hierarchy at three different phases (early-, mid- and latewinter) within the wintering group (consisting of four males from each brood) in order to test two non-mutually exclusive hypotheses:

(1) The maintenance of the within-brood hierarchy within the wintering group. If social relationships in a group are mainly established and maintained during fights (dependent on individual morphological or behavioural traits such as size, aggressiveness; Poisbleau et al. 2005a), we should observe a hierarchical order among siblings within the winter group which is the same as that seen during the duckling period when they were only with their siblings. Moreover, the hierarchical order among all the ducks of the new winter group should be dependent on individual morphological or behavioural traits. Conversely, we should observe a complete reorganisation of the hierarchy among siblings when they join the winter group (1) if winter social relationships are not determined by early social experience or individual morphological or behavioural traits or (2) if relative inter-individual differences in individual traits between ducks (such as relative size or aggressiveness) determine within-brood and winter hierarchies.

(2) Differences in social rank among broods in the winter group. Hatching date, brood size or maternal social rank could influence later adult social status (Velando 2000). Parental quality could influence the social dominance relationships of offspring through various genetic and social traits (Boag 1982), so offspring could inherit the aptitude to dominate from their parents (Barrette 1993). In this case, we would expect siblings to have similar social ranks to each other within the wintering group, and to observe a difference in social ranks between broods. 


\section{Methods}

Study population

The observations were carried out between April 2002 and February 2003 at the Centre d'Etudes Biologiques de Chizé, in western France, using Mallard ducklings descended from individuals caught in the wild three generations previously. Outside of experimental periods, the Mallard population (including the mothers of the six studied broods) was free to move in the field station's yard (approximately $1,000 \mathrm{~m}^{2}$ ) during the day. At night, the ducks were caged in a $200-\mathrm{m}^{2}$ aviary $\left(100 \mathrm{~m}^{2}\right.$ grass, $100 \mathrm{~m}^{2}$ concrete), equipped with a $25-\mathrm{m}^{2}$ pool. This programme was approved by the Ministry of the Environment and satisfied the requirements of the Animal Welfare regulations of the Ministry of Research and Higher Education.

During the first part of the experiment (hereafter the "duckling period"), we followed 56 ducklings from six different broods hatched between 29 April and 31 May (Tables 1,2). We followed each nest from the laying of the first egg to the hatching of the last one. Within $24 \mathrm{~h}$ of its laying, each egg was numbered with a pencil. Each brood was initially left with its natural mother in a nest built by the mother in an individual box provided by the experimenters. As soon as the first egg of a brood started to hatch, the entire clutch was replaced by dummy eggs under the mother and put in separate compartments in an incubator in order to record the hatching order within each brood. Newly-hatched birds remained isolated in an individual box $\left(1 \mathrm{~m}^{2}\right)$ equipped with a heating lamp $\left(28^{\circ} \mathrm{C}\right)$ until the last duckling of the brood was hatched and dried. Colour rings were then fitted to the ducklings and the entire brood was reintroduced under its natural mother while we removed the dummy eggs (within $48 \mathrm{~h}$ of the first hatching of the brood). This incubator hatching also aimed to control for effects of hatching order on the early social experiences of ducklings. Because ducklings remained isolated from each other until the simultaneous reintroduction of all siblings under their mother, their social lives within the brood started simultaneously. Afterwards, ducklings were left together with their mother, with no visual contact with other broods or ducks by day or night, until 30 September (Table 1). Each brood was kept in a $40-\mathrm{m}^{2}$ grass pen during the day and in a $10-\mathrm{m}^{2}$ concrete aviary during the night.

On 30 September (the onset of the "winter period", Table 1), the four most dominant males within each of five broods, excepting brood 5 which contained only two males. These 20 ducks were confined together in a single $50-\mathrm{m}^{2}$ grass pen during the day and in a $50-\mathrm{m}^{2}$ concrete aviary during the night, each equipped with a $10-\mathrm{m}^{2}$ pool. This
Table 1 Key dates during the study

\begin{tabular}{ll}
\hline Events & Dates \\
\hline Hatching period & 29 April to 31 May \\
Brood 1 & 29 April \\
Brood 2 & 6 and 7 May \\
Brood 3 & 7 May \\
Brood 4 & 11 and 12 May \\
Brood 5 & 26 and 27 May \\
Brood 6 & 30 and 31 May \\
Duckling period observations & 3 June to 17 August \\
Formation of the winter & 30 September \\
group with 20 males & 30 September to 28 January \\
Winter period observations & 30 September to 15 October \\
Early-winter phase & 30 October to 21 November \\
Mid-winter phase & 17 January to 28 January \\
Late-winter phase &
\end{tabular}

Brood number 1 is the first to hatch and 6 is the last

Table 2 Analysis of the six within-brood sociometric matrices calculated for the duckling period and of the sociometric matrices calculated for each of the three phases of the winter

\begin{tabular}{lllllc}
\hline Brood & $n_{\text {birds }}$ & $n_{\text {interactions }}$ & $h$ & $h^{\prime}$ & \multicolumn{1}{c}{$P$} \\
\hline 1 & 8 & 314 & 1.00 & 1.00 & 0.0003 \\
2 & 12 & 673 & 0.93 & 0.93 & $<0.0001$ \\
3 & 8 & 479 & 0.81 & 0.81 & 0.0061 \\
4 & 9 & 996 & 0.89 & 0.89 & $<0.0001$ \\
5 & 9 & 465 & 0.86 & 0.86 & 0.006 \\
6 & 10 & 549 & 0.57 & 0.57 & 0.014 \\
Early-winter group & 20 & 1,411 & 0.69 & 0.71 & $<0.0001$ \\
Mid-winter group & 20 & 839 & 0.35 & 0.38 & 0.0003 \\
Late-winter group & 20 & 674 & 0.50 & 0.53 & $<0.0001$ \\
\hline
\end{tabular}

Landau's index $h$ and the index of linearity $h^{\prime}$ are equal during the duckling period because all the dyadic relationships within broods were known. $P$ is the statistical significance of the linearity

excluded the potential effect of sex on social relationships during winter, used the same number of birds per brood and enabled comparison of the new winter social ranks of birds coming from four similar within-brood rank categories. During both periods (duckling/winter) and each captivity condition (aviary/pen), we provided food (crushed corn, wheat and commercial duck food with added vitamins) and water ad libitum at several different points.

Birds were marked as ducklings with individually numbered plastic farm rings on the left leg and, for rapid visual recognition, a coloured ring on the right leg. At the beginning of the winter period, colour rings were removed and birds were marked individually with plastic badges glued on their back with non-toxic glue $(3 \times 6 \mathrm{~cm}$, with black and white codes; Poisbleau et al. 2005a, b), allowing easy visual recognition when birds were videotaped. 
Morphometric measurements

Each duckling was weighed (to the nearest $0.1 \mathrm{~g}$ ) and measured at hatching, then every 3rd day from the age of 3 to 21 days, every 4 th day from 25 to 45 days, every 7 th day from 50 to 80 days, and finally at 90 and 100 days. Here, we use "hatching traits" to describe those measured on the day of hatching, "duckling traits" for those measured during the duckling period and "adult traits" for those measured at the age of 100 days. We measured tarsus and culmen lengths to the nearest $0.01 \mathrm{~mm}$ using an electronic calliper and wing length to the nearest $0.5 \mathrm{~mm}$ with a ruler. The same observer performed all the measurements at the same time of day (1800 hours) in order to minimise bias.

We parameterised the growth of body mass and tarsus, culmen and wing lengths using a Gompertz model (Brown and Rothery 1993) with four parameters according to the equation: $Y=Y_{0}+A \cdot \exp \left\{-\exp .\left[-\left(X-X_{0}\right) / B\right]\right\}$ where $Y_{0}$ is the hatching mass (or length), $A$ is the growth amplitude value between the hatching body mass/size and adult mass/size, $X_{0}$ is the age of the maximum growth rate and $B$ is the maximum growth rate (Gompertz instantaneous growth coefficient, negatively correlated to growth rate). We used $B$ and $X_{0}$ to describe and analyse interindividual differences in duckling growth. Hatching and adult mass/size were better represented by direct measurements than by parameters $Y_{0}$ and $A$. We used tarsus $\times$ culmen $\times$ wing lengths as a body size index $\left(\mathrm{mm}^{3}\right)$ (Poisbleau et al. 2006a, b), calculating body mass and size at 1 day (hatchlings) and 100 days (adults).

During the winter, we report the mean body mass per phase of observation.

\section{Social dominance observations}

During the duckling period, each brood was observed for $2 \mathrm{~h}$ each 2 weeks, spread between three different 40-min sessions at least 2 days apart. These observations were carried out from 0800 to 1000 hours between 3 June and 17 August (Table 1) while birds were in their daytime grass pen. During a session of observation, each observer (from 8 to 12 simultaneous observers according to the brood size, i.e. one per bird) followed one duckling of the brood. This gave a total of $12 \mathrm{~h}$ of behavioural observation per bird during the duckling period. The observers were positioned $2 \mathrm{~m}$ from the enclosure behind an opaque barrier to allow a good distinction of individual colour rings without disturbing the ducklings. At the beginning of each session, we provided a bowl of $700 \mathrm{~g}$ of wheat and a $2-\mathrm{m}^{2}$ bowl of water. We noted all aggressive encounters (threat, chase, fight and/or avoidance) anywhere in the enclosure and recorded the winner and the loser of each of them (after methods described in Poisbleau et al. 2005a, b).
During the winter period, we performed observations from video records of the single winter group during three different phases (Table 1): from 30 September to 15 October (early-winter), from 30 October to 21 November (mid-winter) and from 17 January to 28 January (latewinter). We made 10 different 45-min video records of the group per winter phase (i.e. $7.5 \mathrm{~h}$ per phase). These were spread among the different mornings (between 0800 and 1000 hours) of the winter phase, with only one record per morning. During each session, the group of birds was placed in the same $2 \times 4 \mathrm{~m}$ arena (not familiar to any of them before the first session) and videotaped using a digital video camera recorder (Sony, Digital handycam) positioned $2 \mathrm{~m}$ from the enclosure and $2 \mathrm{~m}$ from the ground to facilitate reading of the badge codes. No observer was visible to the ducks after the camera was positioned. The camera field $(2 \times 2 \mathrm{~m})$ included a bowl of $400 \mathrm{~g}$ of wheat and a $700-\mathrm{cm}^{2}$ bowl of water. For analyses of the social relationships, we combined all types of aggressive encounters (threat, chase, fight and/or avoidance) recorded on the videotapes, determining the winner and loser of each (for more details about the exact methodology, see Poisbleau et al. 2005a, b).

\section{Statistical analyses}

Interactions between birds were organised in six sociometric matrices (one per brood) from which we calculated Landau's index $h$ and the index of linearity $h^{\prime}$ (De Vries 1995), using MatMan 1.0 (De Vries et al. 1993). These indexes express the strength of the linearity present in a set of social relationships and vary from 0 (absence of linearity) to 1 (complete linearity). $h^{\prime}$ is based on $h$ and takes into account the existence of unknown relationships, when two members of a dyad have not been observed to perform any agonistic interaction. Statistical significance of the linearity is provided by an improved linearity test using a sampling process of 10,000 randomisations on the $h^{\prime}$ index (De Vries 1995). When the dominance hierarchy was significantly linear, individuals were reordered by a two-step iterative procedure $(10,000$ sequential trials) according to the number of encounters they won or lost with each opponent. MatMan found the rank order most consistent with a linear hierarchy by minimising the number of inconsistencies and then minimising the total strength of the inconsistencies (De Vries 1998). The birds were ranked from 1 (most dominant) to $n$ (most subordinate).

Most of the parameters from Gompertz models describing the growth of the different morphological traits co-varied. We therefore used the first principal component scores from separate principal component analyses of parameters $B$ and $X_{0}$ as two indexes of the growth characteristics. In the "maximum growth rate" compound 
(PCB), loadings were 0.930 for mass, 0.236 for tarsus length, 0.789 for culmen length and 0.891 for wing length. PCB had an eigenvalue of 2.34 and explained $58.4 \%$ of the variation. In the "age of the maximum growth rate" compound $\left(\mathrm{PCX}_{0}\right)$, loadings were 0.963 for mass, 0.134 for tarsus length, -0.913 for culmen length and 0.961 for wing length. $\mathrm{PCX}_{0}$ had an eigenvalue of 2.70 and explained $67.6 \%$ of the variation.

Social ranks followed a normal distribution without transformation. We first performed a General Linear Mixed Model (Littell et al. 1996) with "brood" as a random factor to test for potential correlates of social rank during both the duckling period and winter. We used Kendall rank partial correlation tests for rank maintenance between different winter phases. All statistical analyses were performed using SYSTAT 7.0 (Wilkinson 1997). Values are presented as mean $\pm \mathrm{SE}$.

\section{Results}

Within-brood social relationships during the duckling period

Ducklings started to perform aggressive encounters (mainly threats, chases and soft fights) with their siblings as soon as they were returned to their mother from the incubator. We observed no obvious changes in the intensity or frequency of these aggressive encounters during the duckling period. The analysis of the six sociometric matrices, in which there were no unknown dyadic relationships (i.e. each duckling met at least once with each other duckling from his brood), revealed a linear hierarchy within each brood (Table 2). All the explanatory variables were non-significant $(P>0.05$, Table 3$)$ and were removed from the model during the backwards stepwise procedure $\left(F_{1,49}=1.592, P=0.213\right.$ for age of maximum growth rate, the last variable removed). Therefore, none of the hatching

Table 3 Test of the effects of hatching and duckling traits on social rank within brood $(n=56)$ during the duckling period

\begin{tabular}{lll}
\hline Effects & $F_{1,44}$ & $P$ \\
\hline Sex & 0.658 & 0.422 \\
Hatching order & 0.180 & 0.673 \\
Hatching body mass & 0.503 & 0.482 \\
Hatching body size & 0.061 & 0.807 \\
Maximum growth rate & 0.846 & 0.363 \\
Age of maximum growth rate & 3.029 & 0.089 \\
\hline
\end{tabular}

Results of the general linear mixed model procedure on social ranks with brood as a random effect. All interactions were non-significant and therefore removed from the full model during the backwards stepwise procedure and duckling traits explained the within-brood dominance hierarchies during the duckling period (Table 3).

Early-winter social relationships

In the early-winter phase, just after the formation of the new winter group with the four most dominant males of five broods, males rapidly reorganised according to a strong linear hierarchy (Table 2). This new organisation within the whole wintering group did not represent the previous hierarchies within broods (Fig. 1). The four initial social rank categories from the duckling period were not maintained during early-winter among birds of the same brood (Fig. 1a). Similarly, the most dominant males in their brood were not among the most dominant birds in the whole group (Fig. 1b).
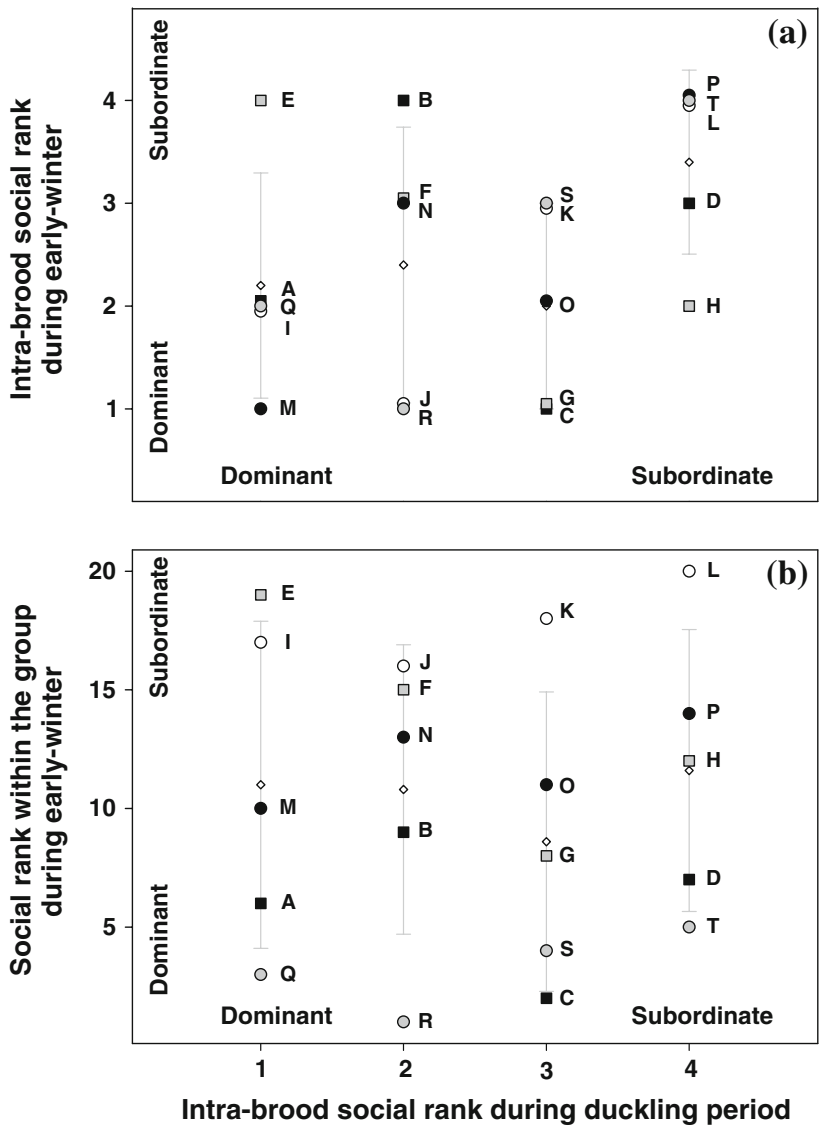

Fig. 1 Social rank during the early-winter phase according to social rank during the duckling period, for the four most dominant males of each brood. a Maintenance of within-brood social relationships among male siblings. b Relationships within the whole group $(n=20$ males). Circles and squares represent individual Mallards while small white diamonds and grey bars represent the mean and standard deviation for each initial within-brood social rank. Ducklings from the same brood are represented by circles or squares with the same fill shade and labelled from $A$ to $T$ where $A$ was the intra-brood dominant of brood 1 and $D$ the subordinate of that brood (and $T$ the intra-brood subordinate of brood 6 , brood 5 being removed from the winter study) 


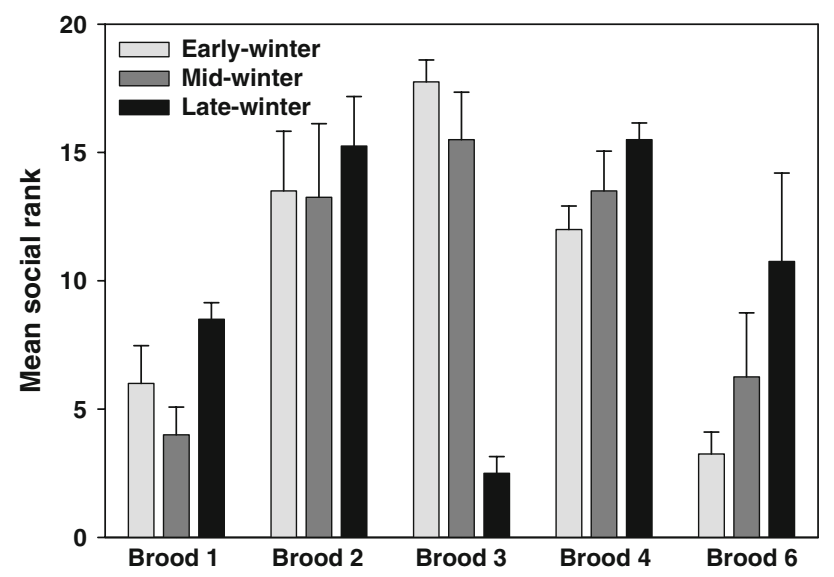

Fig. 2 Mean social rank per brood for the four most dominant males of each brood according to the phase of winter. Low social ranks correspond to high social status and vice versa. Mean $\pm \mathrm{SE}$

Ducklings' social ranks among the whole wintering group differed according to their brood of origin (GLMM, $F_{4,13}=8.063, P=0.002$, Fig. 2 ), but did not correlate to their current body mass (GLMM, $F_{1,13}=0.124, P=0.730$ ) or body size (GLMM, $\left.F_{1,13}=0.114, P=0.741\right)$. On average, broods 6 and 1 had the highest social rank.

Mid-winter social relationships

During mid-winter, males were organised according to a linear hierarchy among the whole wintering group (Table 2). Social rank in mid-winter was correlated with that in early-winter (Kendall rank correlation $\tau=0.695$, $P<0.0001$, Fig. 3a). Only two ducklings moved more than four positions (equivalent to $20 \%$ of the hierarchy): $\mathrm{K}$ rose seven places and $\mathrm{S}$ fell nine (Fig. 3a).

Again, ducklings' social ranks among the whole wintering group differed according to their brood of origin (GLMM, $F_{4,13}=3.253, P=0.047$; Fig. 2 ), but did not correlate to their current body mass (GLMM, $F_{1,13}=0.071$, $P=0.795)$ or body size (GLMM, $F_{1,13}=0.004, P=0.954$ ). On average, the most dominant broods were broods 1 and 6 .

\section{Late-winter social relationships}

During late-winter, males were organised according to a strong linear hierarchy among the whole wintering group (Table 2). The late-winter hierarchy was not significantly correlated with the mid-winter one (Kendall rank correlation $\tau=0.200, P=0.218$; Fig. 3b). Nine ducks moved more than 4 positions: brood 3 (from I to L, white dots in Fig. 3b) rose between 7 and 18 places while five ducklings from two broods (A, C, Q, R and S) fell 5-7 places. Brood 3 was the most subordinate during early- and mid-winter, but became the most dominant during late-winter (Fig. 2).
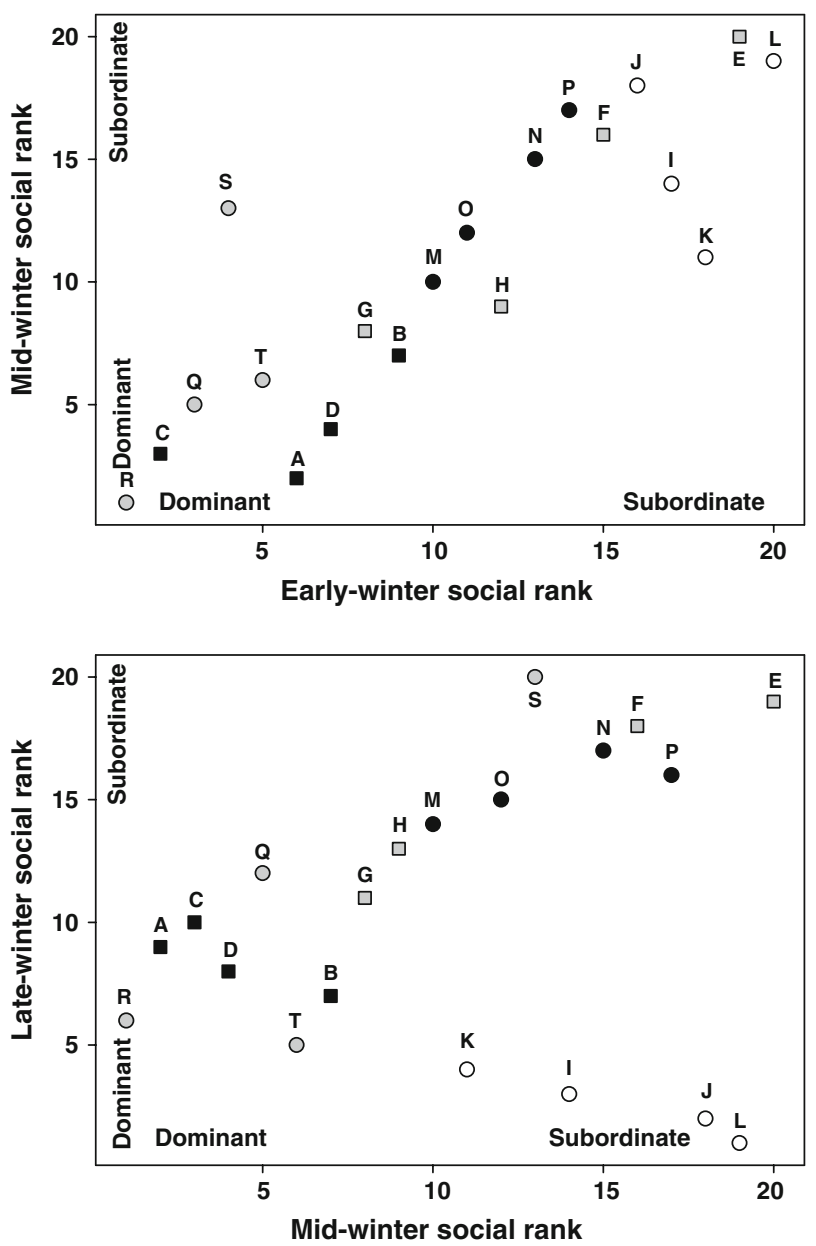

Fig. 3 Maintenance of the individual social ranks of the 20 males $\mathbf{a}$ between the early- and mid-winter phases and $\mathbf{b}$ between the mid- and late-winter phases. Ducklings from the same brood are represented by the same symbol and labelled from $A$ to $T$ where $A$ was the intra-brood dominant of brood 1 and $D$ the subordinate of that brood (and $T$ the intrabrood subordinate of brood 6 , brood 5 being removed from the winter study). On average, the highest-ranking broods were broods 1 and 6 during early- and mid-winter and brood 3 during late-winter

Ducklings' social ranks among the whole wintering group differed according to their brood of origin (GLMM, $F_{4,13}=6.576, P=0.004$; Fig. 2) but did not correlate to their current body mass (GLMM, $F_{1,13}=2.864, P=0.114$ ) or body size (GLMM, $\left.F_{1,13}=2.170, P=0.170\right)$.

\section{Discussion}

Within-brood social relationships during the duckling period

There was a linear dominance hierarchy within each brood, as found in most species of Anseriforms and Galliforms (Drummond 2006). Thus, starting as early as the first few days after hatching, aggressive encounters continued 
through the entire duckling period with the same social relationships. Social ranks were not related to sex during the duckling period, despite the role of this factor in influencing social relationships in adult anatids (Hepp and Hair 1984; Lamprecht 1986), but in accordance with previous observations on young ducks (Hepp 1989). Moreover, none of the measured morphological traits, at hatching or during the duckling period, could significantly explain this organisation. The oldest, biggest or heaviest ducklings at the time of the first encounter between siblings were therefore not necessarily the most dominant individuals within their brood. This result, obtained in a precocial species, contrasts with those generally obtained for altricial birds, in which sibling competition for food can allow dominant siblings to live while subordinates are exposed to death by starvation. Initial size difference may thus have a great impact on social relationships in altricial birds only (Bortolotti 1986a, b; Drummond et al. 1991; Drummond and Osorno 1992). In a similar contrast, Mallard ducklings with faster growth were not dominant over those with slower growth, as opposed to some altricial bird species (Bortolotti 1986a). Most of the ducklings from the same brood hatched within the same 24-h period and all within less than $48 \mathrm{~h}$ (compared to the greater asynchrony of altricial species of a similar size; Bortolotti 1986a, b; Drummond et al. 1991; Drummond and Osorno 1992). We may assume that asynchrony was insufficient in Mallards to generate significant inter-individual differences in initial and future physical characteristics. On the other hand, because ducks are precocial, feed themselves and thus do not show siblicide, they probably do not compete for food or space as intensively as altricial chicks (Drummond 2006). Therefore, an alternative mechanism, not necessarily directly related to fighting abilities, could be the main determinant of the hierarchy organisation.

\section{Winter social relationships}

During the second part of the experiment, we only kept the four most dominant males from each of five broods. Within this new group and later during mid- and late-winter, birds were organised following a linear hierarchy. This result shows that as early as during their first winter, Mallard ducklings may display social relationships and that these relationships could be organised linearly, as are those of adults (Poisbleau et al. 2005a, b). Nevertheless, these subadult males did not maintain a social rank similar to that previously held within their brood: the within-brood hierarchies of the duckling period were not maintained in early-winter, nor was a duckling's rank among the whole early-winter group related to its former within-brood rank. Therefore, in this new social context, we observed a hierarchical reorganisation, even among siblings. As found for young European Shags Phalacrocorax aristotelis (Velando 2000), brood hierarchy did not affect later social rank. In our study, this result is not surprising if we consider that none of the tested "hatching" and "growth" traits explained the within-brood hierarchy. Furthermore, duck family members do not necessarily stay together in their wild wintering grounds (Géroudet 1999), so the mechanisms involved in social relationships during winter could be different or have a different impact from those operating during the duckling period. However, in this study, only four individuals from each brood were followed into winter. These four may have had strong associations with siblings and profited from their active or passive social support in aggressive encounters during the duckling period (Scheiber et al. 2005). If these siblings were more subordinate and afterwards not present in the winter group, we cannot exclude the possibility that the re-arrangement of the social relationships among siblings between the duckling period and the early-winter phase was related to the change in the sibling-group composition between these two periods.

The hierarchical orders between individuals as well as between broods (mean social rank) within the winter group remained almost the same between early- and mid-winter, but changed significantly in late-winter. Dominance hierarchies within broods showed also some interesting instability. For instance, the hierarchy within brood 3 was completely inverted between mid-winter and late-winter, at the same time as this brood shifted from the lowest to the highest rank among the five broods. It is difficult to discuss whether these two inversions were related. Indeed, this brood had also undergone an almost total inversion of its organisation between early-winter and mid-winter without significant change to its mean social rank among the other broods. Moreover, the hierarchies within broods 1 and 6 were also partially inverted between mid-winter and latewinter, but these broods decreased their social status. Finally, as the broods with the most stable organisation (broods 2 and 4) did not change their mean social ranks greatly between the three winter phases, we could suppose that instability within a brood may lead to a change in its average social status but without necessarily predicting the direction of this change.

According to our first and second hypotheses, greater body size and/or mass could be a physical advantage during fights. However, this was not confirmed during our experiments at any time during the winter, with no significant correlations between winter social rank and body size or mass. We must therefore consider other mechanisms which may be involved in early social relationships. For example, the observed changes in social relationships during late winter may be associated with changes in hormone titres. Testosterone titre in male Mallards is 
known to increase by December (Poisbleau et al. 2005a). Indeed, we previously found that morphologic measurements, body mass and body condition were not correlated with individual social ranks during winter whereas social rank was a function of testosterone levels in adults of three dabbling duck species (Mallard, Pintail A. acuta and Wigeon A. penelope; Poisbleau et al. 2005a).

\section{Brood differences}

Mallards had different social ranks according to their brood of origin throughout the winter, but the average social rank of each brood could change between phases (here, between midand late-winter). This underlines once again that the mechanisms involved in social relationships could change between phases, but especially that the main mechanism involved might be "brood-related", i.e. depending on the brood of origin and/or involving an influence of siblings on each other's interactions with non-relatives. Factors potentially responsible for some of these brood differences (e.g. hatching date, brood size and maternal rank) are difficult to discuss here since we have no replication for them. Nevertheless, these differences are interesting to discuss. Brood effects during winter could not be due to passive or active social support by the mother (Weiß and Kotrschal 2004) because mothers were not present during the second part of the experiment. Brood effects might be due to social support by siblings: dominant males may actively interfere in interactions involving their siblings or may tolerate the proximity of siblings more than that of unrelated individuals, having indirect consequences on their siblings' social rank (Scheiber et al. 2005). Our present data do not allow the testing of this hypothesis.

The link between female social status, reproductive strategy and the subsequent social status of offspring remains to be further clarified. A positive impact of maternal social rank often occurs in wildfowl (e.g. Black and Owen 1987), and could be explained by both genetic and environmental influences. Indeed, parental quality has been suggested to affect, through learning and heredity, the physical and social development of ducklings (Black and Owen 1987). Moreover, breeding success in a year increases with early breeding and brood size (e.g. Elmberg et al. 2005 for Teals A. crecca), and dominant females usually have both these advantages (Kokko 1999; Bêty et al. 2003). For example, dominant Japanese Quails produce greater numbers of young as well as a significantly higher proportion surviving to adulthood (Boag 1982). A larger sample size with replication in brood size and hatching date and a large number of females of known social rank would be necessary to test these different hypotheses.

\section{Zusammenfassung}

Die soziale Stellung von Stockentenküken Anas platyrhynchos innerhalb einer Brut und deren Auswirkungen auf die Rangordnung im Winter

Die Jungvögel vieler Arten legen innerhalb der Familie als sozialer Einheit nur eine Rangordnung fest, um nach deren Verlassen konkurrenzstark zu sein und in neuen sozialen Gruppen einen möglichst dominanten Rang zu erlangen. Über die Auswirkung von Geschlecht, Körpermasse, Größe oder Erfahrung während der Kükenperiode auf den späteren Dominanzgrad und die sozialen Beziehungen als Altvogel ist nur wenig bekannt.

Um die Rolle individueller Charakteristika und Wachstumsraten bei der Festlegung von Rangordnungen innerhalb einer Brut, auf die Stabilität dieser Hierarchien in der darauf folgenden Überwinterungsgruppe und auf die Unterschiede im sozialen Rang zwischen verschiedenen Familien zu untersuchen, verwendeten wir Stockenten aus Gefangenschaft. Sehr stabile lineare Rangordnungen gab es innerhalb jeder Brut und später innerhalb jeder Phase des Winters. Zwischen der Kükenperiode und dem frühen Winter kam es zu einer Umstrukturierung der Rangreihenfolge, aber später während des Winters gab es nur wenig Änderung. Keiner der getesteten Schlupf-, Küken- und Altvogelcharakteristika erklärte die Hierarchien innerhalb einer Brut oder die Rangordnung im Winter, aber der Rang im Winter hing mit der Herkunft insofern zusammen, als Küken der selben Brut eine ähnliche soziale Stellung hatten. Diese Unterschiede zwischen den Familien bestanden in den meisten Fällen über den gesamten Winter hindurch fort, lediglich eine Brut stieg im Spätwinter in der Hierarchie weit nach oben. Die Ergebnisse legen nahe, dass andere Faktoren die Etablierung sozialer Beziehungen innerhalb einer Brut beeinflussen, als die in Überwinterungstrupps, und dass brutabhängige Mechanismen die sozialen Beziehungen im Winter beeinflussen. Unsere Ergebnisse diskutieren wir vor dem Hintergrund direkter und indirekter maternaler Einflüsse.

Acknowledgments We are grateful to Sandra Blais, Daphné Durant, Pierre-Yves Perroi, Diane Desmonts, Florian Moreau, Patrice Gaston, Marie-Hélène Burle, Kevin Poisson, Patrice Luccheta and more particularly Noël and Nadine Guillon for their help with manipulation and observation. We also highly appreciated the scientific advice of Hervé Fritz and Marcel M. Lambrechts. We thank Peter H. Becker and two anonymous referees for their substantial comments, which improved the manuscript. The programme was funded by the CNRS and the Office National de la Chasse et de la Faune Sauvage. All the experiments comply with the current laws of France and adhere to the Guidelines for the Use of Animal in Research. 


\section{References}

Appleby MC (1980) Social rank and food access in red deer stags. Behaviour 74:294-309. doi:10.1163/156853980X00519

Archer J (1988) The behavioural biology of aggression. Cambridge University Press, Cambridge

Barash DP (1975) Evolutionary aspects of parental behavior: distraction behavior of the alpine accentor. Wilson Bull 87:367-373

Barrette C (1993) The "inheritance of dominance", or of an aptitude to dominate? Anim Behav 46:591-593. doi:10.1006/anbe.1993.1225

Bernstein IS (1981) Dominance: the baby and the bathwater. Behav Brain Sci 4:419-458

Bêty J, Gauthier G, Giroux J-F (2003) Body condition, migration, and timing of reproduction in snow geese: a test of the conditiondependent model of optimal clutch size. Am Nat 162:110-121. doi: $10.1086 / 375680$

Black JM, Owen M (1987) Determinants of social rank in goose flocks: acquisition of social rank in young geese. Behaviour 102:129-146. doi:10.1163/156853986X00081

Boag DA (1982) How dominance status of Japanese quail influences the viability and dominance status of their offspring. Can J Zool 60:1885-1891

Boag DA, Alway JH (1981) Heritability of dominance status among Japanese quail: a preliminary report. Can J Zool 59:441-444

Bortolotti GR (1986a) Evolution of growth rate in eagles: sibling competition vs. energy considerations. Ecology 67:182-194. doi: $10.2307 / 1938517$

Bortolotti GR (1986b) Influence of sibling competition on nestling sex ratios of sexually dimorphic birds. Am Nat 127:495-507. doi:10.1086/284498

Brodsky LM, Ankney CD, Dennis DG (1988) The influence of male dominance on social interactions in black ducks and mallards. Anim Behav 36:1371-1378. doi:10.1016/S0003-3472(88) 80206-9

Brown D, Rothery P (1993) Models in biology: mathematics, statistics and computing. Wiley, Chichester

Bryant DM, Newton AV (1994) Metabolic costs of dominance in dippers, Cinclus cinclus. Anim Behav 48:447-455. doi: 10.1006/anbe.1994.1258

Buchanan KL, Evans MR, Goldsmith AR, Bryant DM, Rowe LV (2001) Testosterone influences basal metabolic rate in male house sparrows: a new cost of dominance signalling? Proc R Soc Lond B Biol Sci 268:1337-1344. doi:10.1098/rspb.2001.1669

Capitanio JP (1993) More on the relation of inheritance to dominance. Anim Behav 46:600-602. doi:10.1006/anbe.1993.1228

Creel S (2001) Social dominance and stress hormones. Trends Ecol Evol 16:491-497. doi:10.1016/S0169-5347(01)02227-3

D'Eath RB, Lawrence AB (2004) Early life predictors of the development of aggressive behaviour in the domestic pig. Anim Behav 67:501-509. doi:10.1016/j.anbehav.2003.06.010

De Vries H (1995) An improved test of linearity in dominance hierarchies containing unknown or tied relationships. Anim Behav 50:1375-1389. doi:10.1016/0003-3472(95)80053-0

De Vries H (1998) Finding a dominance order most consistent with a linear hierarchy: a new procedure and review. Anim Behav 55:827-843. doi:10.1006/anbe.1997.0708

De Vries H, Netto WJ, Hanegraaf PLH (1993) MatMan: a program for the analysis of sociometric matrices and behavioural transition matrices. Behaviour 125:157-175. doi:10.1163/156853993 X00218

de Wall FBM (1989) Dominance "style" and primate social organisation. In: Standen V, Foley RA (eds) Comparative socioecology: the behavioural ecology of humans and other mammals. Blackwell, Oxford, pp 243-263
Dewsbury DA (1994) A final word on the inheritance of dominance. Anim Behav 48:984-985. doi:10.1006/anbe.1994.1326

Drummond H (2006) Dominance in vertebrate broods and litters. Q Rev Biol 81:3-32. doi:10.1086/503922

Drummond H, Osorno JL (1992) Training siblings to be submissive losers: dominance between booby nestlings. Anim Behav 44:881-893. doi:10.1016/S0003-3472(05)80584-6

Drummond H, Osorno J, Garcia C, Avilez R (1991) Sexual size dimorphism and sibling competition: implications for avian sex ratios. Am Nat 138:623-641. doi:10.1086/285238

Elmberg J, Nummi P, Pöysa H, Gunnarsson G, Sjöberg K (2005) Early breeding teal Anas crecca use the best lakes and have the highest reproductive success. Ann Zool Fenn 42:1-7

Géroudet P (1999) Les palmipèdes d'Europe, 4th edn edn. Delachaux et Niestlé, Lausanne

Getty T, Capaldi EA (1994) Inheritance of rank requires inheritance of social environment. Anim Behav 48:982-983. doi:10.1006/ anbe.1994.1325

Hepp GR (1989) Benefits, costs, and determinants of dominance in American black ducks. Behaviour 109:222-234. doi:10.1163/ 156853989 X00240

Hepp GR, Hair JD (1984) Dominance in wintering waterfowl (Anatini): effects on distribution of sexes. Condor 86:251-257. doi: $10.2307 / 1366992$

Hoysak DJ, Ankney CD (1996) Correlates of behavioural dominance in mallards and American black ducks. Anim Behav 51:409_ 419. doi:10.1006/anbe.1996.0038

Huntingford F, Turner A (1987) Animal conflict. Chapman \& Hall, London

Kalas S (1977) Ontogenie und Funktion der Rangordnung innerhalb einer Geschwisterschar von Graugänsen (Anser anser). Z Tierpsychol 45:174-198

Kokko H (1999) Competition for early arrival in migratory birds. J Anim Ecol 68:940-950. doi:10.1046/j.1365-2656.1999.00343.x

Kotrschal K, Hemetsberger J, Dittami J (1993) Food exploitation by a winter flock of greylag geese: behavioral dynamics, competition and social status. Behav Ecol Sociobiol 33:289-295. doi: 10.1007/BF00172926

Krause J, Ruxton GD (2002) Living in groups. Oxford University Press, Oxford

Lamprecht J (1986) Structure and causation of the dominance hierarchy in a flock of bar-headed geese (Anser indicus). Behaviour 96:28-48. doi:10.1163/156853986X00207

Littell RC, Milliken GA, Stroup WW, Wolfinger RD (1996) SAS systems for mixed models. SAS institute, Cary

Moore AJ (1993) Towards an evolutionary view of social dominance. Anim Behav 46:594-596. doi:10.1006/anbe.1993.1226

Piper WH (1997) Social dominance in birds. Early findings and new horizons. In: Nolan V Jr, Ketterson ED, Thompson CF (eds) Current ornithology. Plenum Press, New York, pp 125-187

Poisbleau M, Fritz H, Guillemain M, Lacroix A (2005a) Testosterone and linear social dominance status in captive male dabbling ducks in winter. Ethology 111:493-509. doi:10.1111/j.14390310.2005.01092.x

Poisbleau M, Fritz H, Guillon N, Chastel O (2005b) Linear social dominance hierarchy and corticosterone responses in male mallards and pintails. Horm Behav 47:485-492. doi:10.1016/ j.yhbeh.2005.01.001

Poisbleau M, Fritz H, Dano S, Lambrechts MM (2006a) Body measurements and hormonal within-pair covariation in wintering and spring staging dark-bellied brent geese Branta bernicla bernicla. Ardea 94:127-131

Poisbleau M, Fritz H, Lambrechts MM, Trouvé C, Ebbinge BS (2006b) Changes in body mass and hormone levels between wintering and spring staging areas in dark-bellied brent geese 
Branta bernicla bernicla. J Avian Biol 37:143-148. doi:10.1111/ j.0908-8857.2006.03679.x

Rowell TE (1974) The concept of social dominance. Behav Biol 11:131-154. doi:10.1016/S0091-6773(74)90289-2

Scheiber IBR, Weiß BM, Frigerio D, Kotrschal K (2005) Active and passive social support in families of greylag geese (Anser anser). Behaviour 142:1535-1557. doi:10.1163/15685390577 4831873

Stahlberg B-M (1974) The development of rank order and aggressiveness in a group of juvenile greylag geese. Wildfowl $25: 67-73$
Tinkler E, Montgomery WI, Elwood RW (2007) Shared or unshared parental care in overwintering brent geese (Branta bernicla hrota). Ethology 113:368-376. doi:10.1111/j.1439-0310.2007.01324.x

Velando A (2000) The importance of hatching date for dominance in young shags. Anim Behav 60:181-185. doi:10.1006/anbe.2000. 1445

Weiß BM, Kotrschal K (2004) Effects of passive social support in juvenile greylag geese (Anser anser): a study from fledging to adulthood. Ethology 110:429-444. doi:10.1111/j.1439-0310. 2004.00979.x

Wilkinson L (1997) Systat 7.0, New Statistics. SPSS, Chicago 